Pesq. Vet. Bras. 30(10):816-826, outubro 2010

\title{
Defeitos congênitos diagnosticados em ruminantes na Região Sul do Rio Grande do Sul ${ }^{1}$
}

\author{
Clairton Marcolongo-Pereira ${ }^{2}$, Ana Lucia Schild ${ }^{3 *}$, Mauro Pereira Soares ${ }^{3}$, \\ Sergio F. Vargas Jr. ${ }^{4}$ e Franklin Riet-Correa ${ }^{5}$
}

\begin{abstract}
Marcolongo-Pereira C., Schild A.L., Soares M.P., Vargas Jr S.F. \& RietCorrea F. 2010. [Congenital defects in ruminants in southern Brazil.] Defeitos congênitos diagnosticados em ruminantes na Região Sul do Rio Grande do Sul. Pesquisa Veterinária Brasileira 30(10):816-826. Laboratório Regional de Diagnóstico, Faculdade de Veterinária, Universidade Federal de Pelotas, Campus Universitário s/n, Pelotas, RS 96010-900, Brazil. E-mail: alschild@ terra.com.br

Congenital defects in cattle, sheep and buffalo were studied through a review of necropsy files of the Regional Diagnostic Laboratory of the Veterinary Faculty at the Federal University of Pelotas between 1978 and 2009. The occurrence of congenital defects in cattle, sheep and buffalo were $0.88 \%, 0.36 \%$, and $7.54 \%$, respectively, from all specimens received. Cattle congenital defects of undetermined etiology represented $45.83 \%$ of the congenital defects, known hereditary and probably hereditary diseases represented $6.25 \%$, and $29.16 \%$, respectively, and defects associated to environmental factors represented $16.66 \%$. In cattle, of the 48 congenital defects observed 21 (43.75\%) affected the skeletal system (chondrodysplasia, scoliosis, lateral deviation of the mandible, palatoschisis and unclassified defect), nine (18.75\%) affected the central nervous system (hypoplasia of olfatory and frontal lobes, cerebellar cortical degeneration, spina bifida, congenital hypomielinogenesis, hereditary hypermetria, cerebellar hypoplasia, and pachygiria), nine $(18.75 \%)$ the muscular system (arthrogryposis), three (6.25\%) the cardiovascular system (patent ductus arteriosus and unclassified malformation), one (2.08\%) the lymphatic system (hereditary lymphatic hypoplasia), one (2.08\%) the alimentary system (atresia ani), and one $(2.08 \%)$ the eye (congenital blindness). In five cases $(10.41 \%)$ different systems were affected (diprosopus). Different hereditary diseases (hereditary hypermetry, arthrogryposis, and lymphatic hypoplasia) or diseases suspected of being hereditary (chondrodysplasia) were diagnosed in cattle. Also occurred, with less frequency, congenital defects associated with environmental factors (hypomyelinogenesis due to cooper deficiency) or probably environmental factors (cleft palate, cerebellar hypoplasia, and cerebellar cortical degeneration). In sheep all observed defects were sporadic and affected various systems (anomalous twins and aprosopia). In buffalo all congenital defects were hereditary (arthrogryposis, myotonia and mechano-bullous genodermatoses) or suspected of being hereditary (albinism, megaesophagus and hydranencephaly/cerebellar hypoplasia). It is concluded that sporadic congenital defects are not important in the three species studied. Despite the low frequency congenital defects associated with environmental factors could
\end{abstract}

\footnotetext{
${ }^{1}$ Recebido em 22 de abril de 2010.

Aceito para publicação em 19 de maio de 2010.

Parte da Tese de Mestrado do primeiro autor, Programa de Pós-Graduação em Veterinária, Faculdade de Veterinária, Universidade Federal de Pelotas (UFPel), Campus Universitário $s / n$, Pelotas, RS 96010-900, Brasil.

2 Doutorando do Curso de Pós-Graduação em Veterinária, Faculdade de Veterinária, UFPel, Pelotas, RS.
}

\footnotetext{
3 Laboratório Regional de Diagnóstico, Faculdade de Veterinária, UFPel, Pelotas, RS96010-900. *Autor para correspondência: alschild@ terra.com.br

${ }^{4}$ Graduando em Veterinária, Faculdade de Veterinária, UFPel, Pelotas, RS. Bolsista de Iniciação Científica (PIBIC/CNPq).

${ }^{5}$ Hospital Veterinário, Centro de Saúde e Tecnologia Rural (CSTR), Universidade Federal de Campina Grande, Patos, PB 58700-000, Brasil.
} 
be important in some regions or farms. Hereditary or probably hereditary diseases are important, not only by the mortality rates, but also because the risk of dissemination of the genes in the different breeds. In water buffalo the high prevalence of hereditary diseases was a consequence of the high consanguinity of the Brazilian buffalo population. Control measures need to be taken to avoid the spread of recessive genes in cattle and buffalo.

INDEX TERMS: Congenital defects, hereditary diseases, ruminants, pathology, epidemiology.

RESUMO.- Foi realizado um estudo dos defeitos congênitas diagnosticados em bovinos, ovinos e bubalinos mediante revisão dos protocolos de necropsia do Laboratório Regional de Diagnóstico da Faculdade de Veterinária da Universidade Federal de Pelotas entre 1978 e 2009. A ocorrência de defeitos congênitos em bovinos, ovinos e bubalinos representou $0,88 \%, 0,36 \%$ e $7,54 \%$ respectivamente, de todos os materiais dessas espécies recebidos. Em bovinos os defeitos esporádicos representaram $45,83 \%$ dos diagnósticos, os hereditários $6,25 \%$, os provavelmente hereditários $29,16 \%$ e os ambientais ou provavelmente ambientais $16,66 \%$. Dos 48 casos de defeitos congênitos diagnosticados em bovinos 21 (43,75\%) afetaram o sistema esquelético (condrodisplasia, escoliose, desvio lateral da mandíbula, fenda palatina e malformação não classificada), nove $(18,75 \%)$ o sistema nervoso central (hipoplasia dos lobos frontais e olfatórios, degeneração cerebelar cortical, espinha bífida, hipomielinogênese congênita, hipermetria hereditária, hipoplasia cerebelar e paquigiria), nove $(18,75 \%)$ o sistema muscular (artrogripose), três $(6,25 \%)$ o sistema cardiovascular (persistência do ducto arterioso e malformação não classificada), um (2,08\%) o sistema linfático (hipoplasia linfática), um $(2,08 \%)$ o sistema gastrintestinal (atresia anal), e, um $(2,08 \%)$ o olho (catarata congênita). Em cinco casos (10,41\%) vários sistemas estavam afetados (diprosopo). Em bovinos foram diagnosticadas diversas doenças hereditárias (hipermetria hereditária, artrogripose, hipoplasia linfática) ou suspeitas de serem hereditárias (condrodisplasia). Ocorreram, também, com menor freqüência, defeitos congênitos de origem ambiental (hipomielinogenese, por carência de cobre) ou possivelmente ambiental (fenda palatina, hipoplasia cerebelar, degeneração cerebelar cortical). Todos os casos de defeitos congênitos observados em ovinos (gêmeos anômalos e aprosopia) afetaram vários sistemas e eram esporádicos. Em bubalinos todas as malformações diagnosticadas são hereditárias (artrogripose, miotonia e dermatose mecânico-bolhosa) ou suspeitas de serem hereditárias (albinismo, megaesôfago e hidranencefalia/ hipoplasia cerebelar). Concluiu-se que os defeitos congênitos esporádicos têm pouca importância nas três espécies e que defeitos congênitos de causas ambientais, apesar de pouco freqüentes, podem trazer prejuízos econômicos importantes em determinadas regiões ou estabelecimentos. As doenças hereditárias são importantes não só pela mortalidade mas, também, pela possibilidade de disseminação de genes indesejáveis nas diferentes raças. Em bubalinos a alta frequência de doenças hereditárias na raça Murrah foi atribuída a alta consanguinidade do rebanho brasileiro. Medidas de controle devem ser tomadas para evitar-se a contínua disseminação, principalmente dos genes recessivos, em bubalinos e bovinos.

TERMOS DE INDEXAÇÃO: Defeitos congênitos, doenças hereditárias, ruminantes, patologia, epidemiologia.

\section{INTRODUÇÃO}

Anomalias congênitas têm distribuição mundial e podem causar aborto ou morte neonatal levando à perdas reprodutivas consideráveis (Jolly 2002). A ocorrência de defeitos congênitos em bovinos e ovinos está estimada entre $0,2 \%$ e $3 \%$ e $0,2 \%$ e $2 \%$, respectivamente, em todo o mundo e seu conhecimento depende da frequência com que os mesmos são estudados e descritos (Leipold \& Dennis 1986).

Animais com defeitos congênitos têm provocado grande curiosidade através dos tempos e o diagnóstico é um desafio na moderna prática veterinária. Individualmente, a maioria dos defeitos ocorre raramente e alguns são tão raros que são observados em poucas oportunidades (Leipold et al. 1972). Somente em condições incomuns, quando um determinado defeito ocorre repetidamente em um mesmo rebanho ou área geográfica torna-se alvo de investigação e por essa razão a maioria desses defeitos não é descrita e poucos são os registros de sua ocorrência (Leipold et al. 1983).

Até o início da década de 1960 os defeitos congênitos em bovinos eram na sua grande maioria atribuídos a herança genética e a partir daí, com a descoberta de que a talidomida induzia malformações no homem, houve consenso na comunidade científica mundial de que os defeitos congênitos nas diversas espécies animais não eram necessariamente de origem genética (Leipold et al. 1983).

Trabalhos de revisão realizados na década de 1980 revelaram quatro principais deficiências com relação ao conhecimento dos defeitos congênitos nos animais domésticos: 1) informação inadequada, ou seja, poucos casos relatados; 2) inadequada descrição anátomo-patológica; 3) inadequada análise genética; e 4) falha na interpretação dos achados que contribuem para o entendimento e associação entre os processos embriológicos, patológicos e de natureza genética (Leipold et al. 1983).

No Brasil a informação sobre ocorrência de defeitos congênitos é escassa. Malformações ósseas em ruminantes têm sido relatadas no Nordeste em consequência da ingestão de Mimosa tenuiflora (Pimentel et al. 2007, Dantas et al. 2010). São relatadas, também, malformações na mandíbula em caprinos e ovinos na Bahia (Magalhães et al. 2008). Alguns trabalhos relatam ocorrência esporádica de malformações em bovinos e ovinos (Castro et al. 2008, Pavarinni et al. 2008, Lucena et al. 2009, Dantas et al. 2010). 
Os objetivos desse trabalho foram descrever os aspectos epidemiológicos e a patologia dos defeitos congênitos observados em ruminantes entre 1978 e 2009 na área de influência do Laboratório Regional de Diagnóstico (LRD) da Faculdade de Veterinária da Universidade Federal de Pelotas (UFPel), bem como classificar estes defeitos com base no sistema afetado avaliando sua importância econômica. As doenças hereditárias e/ou de causa ambiental diagnosticadas no LRD descritas anteriormente serão aqui abordadas apenas do ponto de vista da classificação.

\section{MATERIAL E MÉTODOS}

Foi realizado um levantamento dos defeitos congênitos e/ou doenças hereditárias em bovinos, ovinos e bubalinos diagnosticados no Laboratório Regional de Diagnóstico (LRD) da Faculdade de Medicina Veterinária, Universidade Federal de Pelotas (UFPel), de janeiro de 1978 a dezembro de 2009.

Para o estudo epidemiológico dos casos observados foi realizada revisão nos protocolos de necropsia do LRD/UFPel obtendo-se informações referentes à procedência dos animais, ao tipo de manejo utilizado, técnicas de reprodução (monta natural, inseminação artificial), tipo de criação (intensiva, semiintensiva, extensiva), aplicação de vacinas e medicamentos e tipo de alimentação (campo nativo, pastagem, concentrados), quando estes dados constavam nos protocolos. De acordo com evidências epidemiológicas, comprovação através de experimentos ou, ainda, com base na literatura consultada os defeitos congênitos foram considerados esporádicos (sem causa definida), ambientais ou provavelmente ambientais (causados por vírus ou carências minerais ou intoxicações), hereditários e provavelmente hereditários.

Os diferentes defeitos congênitos observados foram classificados de acordo com o sistema afetado, resgatando-se dos protocolos de necropsia os dados relativos aos sinais clínicos, quando os animais sobreviviam após o nascimento e a patologia macroscópica de cada caso. Foram utilizadas, também, para este estudo, fotografias existentes no acervo do LRD.

Quando dois sistemas estavam afetados em um só indivíduo ambos eram considerados para o cálculo do percentual de cada sistema afetado. Quando mais de dois sistemas estava afetado o percentual foi calculado sem especificar-se um sistema.

Nos casos em que as lesões afetavam órgãos ou tecidos e não a estrutura foi realizado o estudo histológico utilizando-se as técnicas de rotina.

\section{RESULTADOS}

Entre janeiro de 1978 e novembro de 2009 foram recebidos 5.409 materiais de bovinos, 843 materiais de ovinos e 106 de bubalinos para análise no LRD. Desse material, $1.121(20,72 \%)$ corresponderam a necropsias em bovinos, $310(36,77 \%)$ a necropsias em ovinos e $61(57,54 \%)$ a necropsias em bubalinos.

Dos 1.121 bovinos necropsiados, 48 (4,28\%) apresentaram malformações congênitas. Dos 61 bubalinos oito $(13,11 \%)$ foram diagnosticados com defeitos congênitos e dos 310 ovinos três $(0,97 \%)$ foram diagnosticados com defeitos congênitos.

Os defeitos congênitos e doenças hereditárias obser- vados em bovinos, ovinos e bubalinos foram classificados de acordo com o sistema afetado e são apresentados nos Quadros 1, 2 e 3, respectivamente.

Dos 48 casos de malformações congênitas observados em bovinos 22 (45,83\%) foram considerados defeitos esporádicos sem identificação de suas causas, 14 $(29,16 \%)$ provavelmente hereditários, oito ambientais $(16,66 \%)$, três hereditários $(6,25 \%)$, e um $(2,08 \%)$ ambiental ou pela interação genético-ambiental.

Os bovinos com defeitos congênitos esporádicos eram provenientes de diferentes municípios da região Sul do Rio Grande do Sul, afetando apenas um indivíduo, sem histórico nas propriedades de ocorrência de casos similares. Destes artrogripose, associada ou não a outros defeitos e diprosopo (Fig.1) foram diagnosticadas em seis (Casos 1, 2, 6, 7, 8 e 9) e cinco (Casos 27, 28, 29, 30 e 31) oportunidades, respectivamente.

Dois casos de artrogripose foram atribuídos a causas provavelmente ambientais, um deles (Caso 3) era o segundo bovino nascido com o mesmo problema na propriedade, filho de uma vaca que já havia tido um bezerro com o mesmo defeito e o tipo de criação na propriedade era extensivo; e o outro (Caso 5) era proveniente de uma propriedade cujo rebanho Charolês tinha diagnóstico de hipoplasia cerebelar (Caso 39) causada provavelmente pelo vírus da diarréia viral bovina (Schild et al. 2001b). Quatro bovinos apresentaram artrogripose hereditária (Caso 4) causada por um gene recessivo autossômico. Estes casos ocorreram em um experimento de retrocruzamento para determinar a origem hereditária de uma degeneração cerebelar congênita. No retrocruzamento não nasceu nenhum animal com degeneração cerebelar (Schild et al. 2001a), mas nasceram quatro bezerros (10,52\%) com artrogripose, comprovando que o touro, da raça Holandês, era heterozigoto para um gene que transmitia a artrogripose (Schild et al. Dados não publicados). Os demais defeitos de origem hereditária foram diagnosticados em duas oportunidades tendo sido descritos previamente: hipoplasia linfática em bovinos Hereford (Caso 43) (Schild et al. 1991); e hipermetria hereditária em bovinos Shorthorn (Caso 36) (Schild et al. 1993). Degeneração cerebelar cortical (Caso 26), também descrita anteriormente, foi atribuída a fatores ambientais ou interação genético-ambiental (Schild et al. 2001a).

Condrodisplasia foi diagnosticada em 14 oportunidades e atribuída a causa provavelmente hereditária. Os Casos 14,23 e 24 foram caracterizados como condrodisplasia tipo bulldog (Fig. 2A) e os demais (Casos 12, 13, 15, 16, 17, 18, $19,20,21,22$ e 25) foram caracterizados como tipo Telemark (Fig.2B). O defeito foi observado na raça Jersey em todos os bovinos com exceção do Caso 21 que era da raça Shorthorn e do Caso 15 em que não havia a indicação da raça no protocolo de necropsia. Os bovinos afetados, com exceção do Caso 21, eram provenientes de pequenas propriedades dos municípios da região Sul do Estado que compõe a bacia leiteira de Pelotas. No Caso 12 não constava a procedência do bovino no protocolo de necropsia. 


\section{Quadro 1. Defeitos congênitos/doenças hereditárias observados em bovinos na área de influência do Laboratório Regional de Diagnóstico da Faculdade de Veterinária da Universidade Federal de Pelotas entre 1978 e 2009}

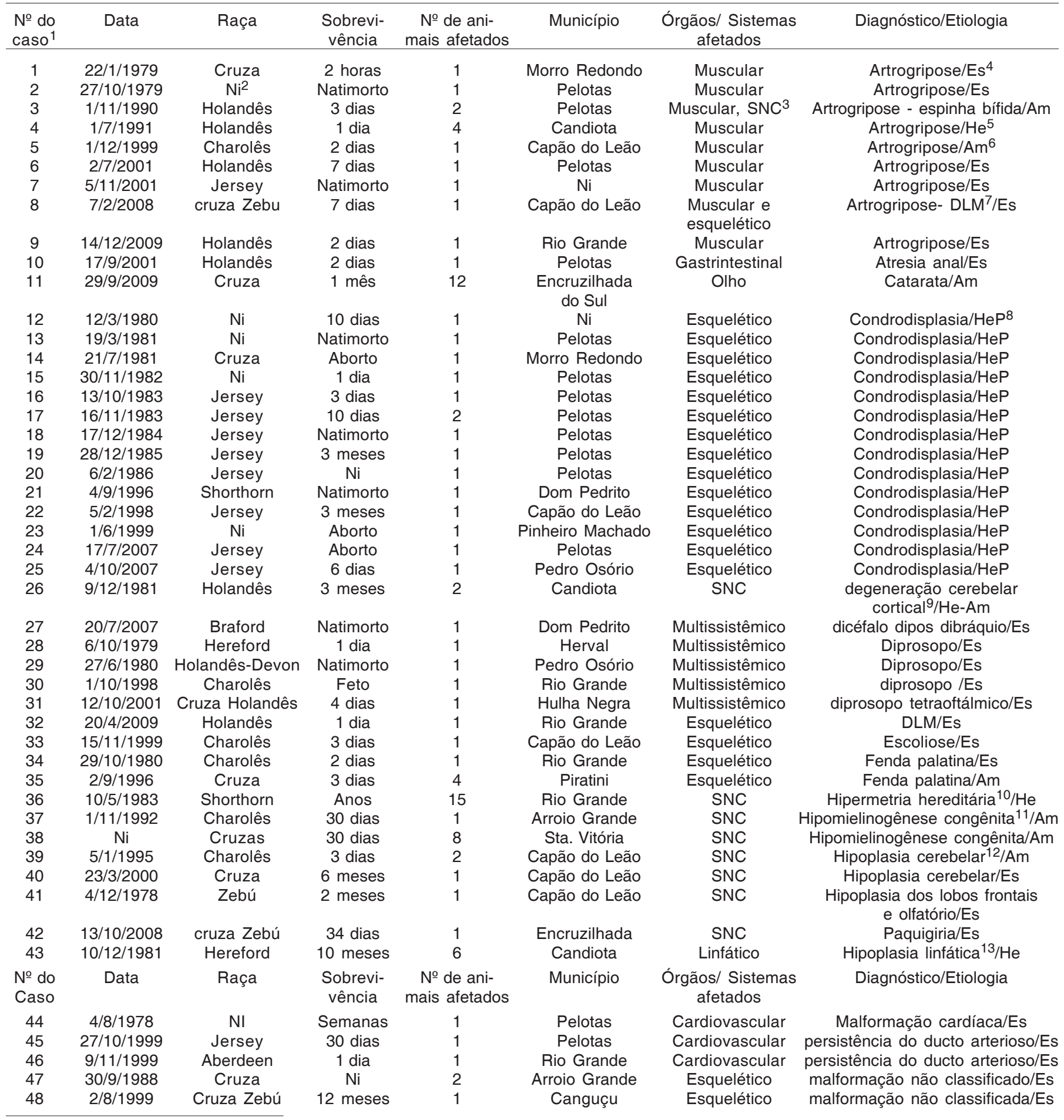

${ }^{1}$ Os casos correspondem a defeitos congênitos individuais ou a surtos observados em uma mesma propriedade, ${ }^{2} \mathrm{Ni}=$ não informa do, ${ }^{3} \mathrm{SNC}$ = Sistema Nervoso Central, ${ }^{4}$ Es-esporádico, ${ }^{5} \mathrm{He}$-hereditário, ${ }^{6} \mathrm{Am}=$ ambiental, ${ }^{7} \mathrm{DLM}=$ desvio lateral da mandíbula, ${ }^{8} \mathrm{HeP}=$ hereditário provável, ${ }^{9}$ Schild et al. (2001a), ${ }^{10}$ Schild et al. (1993), ${ }^{11}$ Riet-correa et al. (1993), ${ }^{12}$ Schild et al. (2001b), ${ }^{13}$ Schild et al. (1991).

Em dois casos (47 e 48) não havia descrição no protocolo de necropsia do defeito observado no sistema esquelético não sendo possível realizar a classificação da malformação. Independente da malformação ser esporádica, ambien- tal ou hereditária, dos 48 casos de defeitos congênitos diagnosticados em bovinos, 21 (43,75\%) afetaram o sistema esquelético (condrodisplasia, escoliose, desvio lateral da mandíbula [Fig.3A,B]), fenda palatina e malformação não 


\section{Quadro 2. Defeitos congênitos/doenças hereditárias observados em ovinos na área de influência do Laboratório Regional de Diagnóstico da Faculdade de Veterinária da Universidade Federal de Pelotas entre 1978 e 2009}

\begin{tabular}{|c|c|c|c|c|c|c|c|}
\hline $\begin{array}{l}\text { № do } \\
\text { caso }\end{array}$ & Data & Raça & $\begin{array}{l}\text { Sobrevi- } \\
\text { vência }\end{array}$ & $\begin{array}{c}\text { № de } \\
\text { animais } \\
\text { afetados }\end{array}$ & Município & $\begin{array}{l}\text { Órgãos/ Sistemas } \\
\text { afetados }\end{array}$ & Diagnóstico/Etiologia \\
\hline 1 & 04-07-1986 & $\mathrm{Ni}^{1}$ & $\mathrm{Ni}$ & 1 & $\mathrm{Ni}$ & Multissistêmico & Gêmeos anômalos/Es 2 \\
\hline 2 & $29-10-2001$ & Corriedale & $1 \mathrm{dia}$ & 1 & $\mathrm{Ni}$ & Multissistêmico & $\begin{array}{l}\text { Gêmeos anômalos } \\
\text { (sincéfalo dípigo)/Es }\end{array}$ \\
\hline 3 & $30-10-2007$ & $\mathrm{Ni}$ & Natimorto & 1 & Capão do Leão & Multissistêmico & Aprosopia/Es \\
\hline
\end{tabular}

Quadro 3. Defeitos congênitos/doenças hereditárias observados em bubalinos na área de influência do Laboratório Regional de Diagnóstico da Faculdade de Veterinária da Universidade Federal de Pelotas entre 1978 e 2009

\begin{tabular}{|c|c|c|c|c|c|c|c|}
\hline $\begin{array}{l}\text { № do } \\
\text { caso }^{1}\end{array}$ & Data & Raça & Sobrevivência & $\begin{array}{l}\text { Animais } \\
\text { afetados }\end{array}$ & Município & Órgãos/ Sistemas & $\begin{array}{c}\text { Diagnóstico/Etiologia } \\
\text { afetados }\end{array}$ \\
\hline 1 & 20-10-1995 & Murrah & Natimorto & 3 & Capão do Leão & Muscular & Artrogripose $\mathrm{e}^{2} / \mathrm{He}^{3}$ \\
\hline 2 & 28-04-1995 & Murrah & Anos & 4 & Capão do Leão & Muscular & Miotonia hereditária/ He \\
\hline 3 & $28-03-2003$ & Murrah & Anos & 25 & Pedro Osório & Muscular & Miotonia hereditária/ He \\
\hline 4 & 20-03-2000 & Murrah & Anos & 13 & Capão do Leão & $\begin{array}{l}\text { Tegumentar e } \\
\text { fotorreceptor }\end{array}$ & Albinismo/ $\mathrm{HeP}^{4}$ \\
\hline 5 & $22-09-2000$ & Murrah & 3-4 anos & 4 & Capão do Leão & Tegumentar & $\begin{array}{c}\text { Dermatose mecânico- } \\
\text { bolhosa } / \mathrm{He}\end{array}$ \\
\hline 6 & $18-02-2004$ & Murrah & 1- 4 dias & 6 & Capão do Leão & SNC & $\begin{array}{c}\text { Hidranencefalia/hipoplasia } \\
\text { cerebelar/ HeP }\end{array}$ \\
\hline 7 & 19-04-2009 & Murrah & 1- 4 dias & 1 & $\begin{array}{l}\text { Capão do Leão } \\
\text { fotorreceptor }\end{array}$ & $\begin{array}{l}\text { SNC/ Tegumentar e } \\
\text { Albinismo/HeP }\end{array}$ & Hidranencefalia/ \\
\hline 8 & 07-12-1995 & Murrah & 8-10 meses & 3 & Capão do Leão & Gastrintestinal & Megaesôfago /HeP/Am 6 \\
\hline
\end{tabular}

${ }^{1}$ Os casos correspondem a defeitos congênitos individuais ou a surtos observados em uma mesma propriedade, 2 Schild et al. (2003), ${ }^{3} \mathrm{He}=$ hereditário, ${ }^{4} \mathrm{HeP}=$ hereditário provável, ${ }^{5}$ Riet-Correa et al. (1994), ${ }^{6} \mathrm{Am}=$ ambiental.

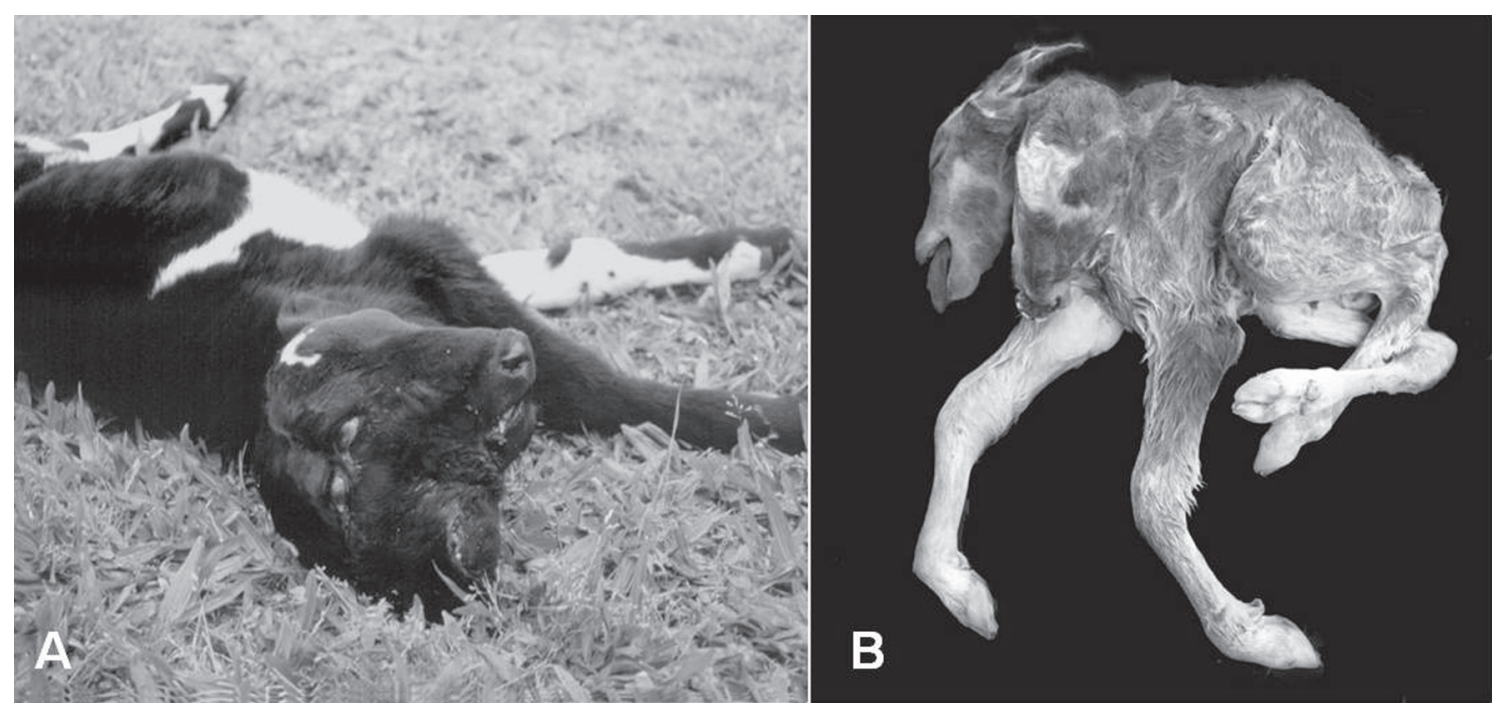

Fig.1. (A) Diprosopo tetraoftálmico (Bovino 31). As cabeças estão unidas na altura dos ossos frontal, parietal e temporal. (B) Dicéfalo dipos dibraquios (Bovino 27). Há duas cabeças separadas e artrogripose.

classificada), nove (18,75\%) o sistema nervoso central (hipoplasia dos lobos frontais e olfatórios, degeneração cerebelar cortical, espinha bífida, hipomielinogênese congênita, hipermetria hereditária, hipoplasia cerebelar e paquigiria [Fig.4]), nove (18,75\%) o sistema muscular (artrogripose), três $(6,25 \%)$ o sistema cardiovascular (persistência do ducto arterioso e malformação não classificada), um (2,08\%) o sistema linfático (hipoplasia linfática), um $(2,08 \%)$ o sistema gastrintestinal (atresia anal), e um $(2,08 \%)$ o olho (catarata congênita) (Fig.5). Em cinco casos (10,41\%) vários sis- 

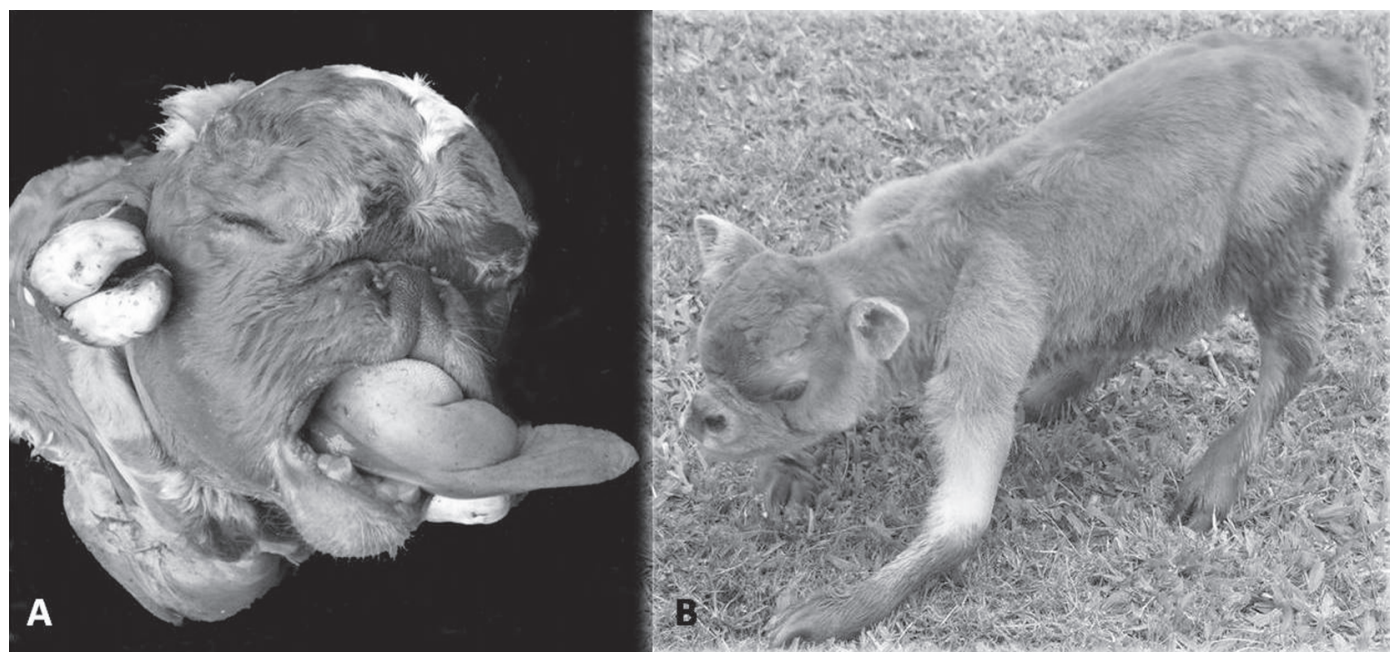

Fig.2. (A) Condrodisplasia tipo Dexter (Bovino 23) O crânio é grande e redondo, o focinho é curto, há protrusão completa da língua e dentes malformados voltados para fora, os membros são muito curtos. (B) Condrodisplasia tipo Telemark (Bovino 20). Há encurtamento dos membros e rotação dos anteriores. Os ossos da cabeça são arredondados, há exoftalmia e o focinho é curto.

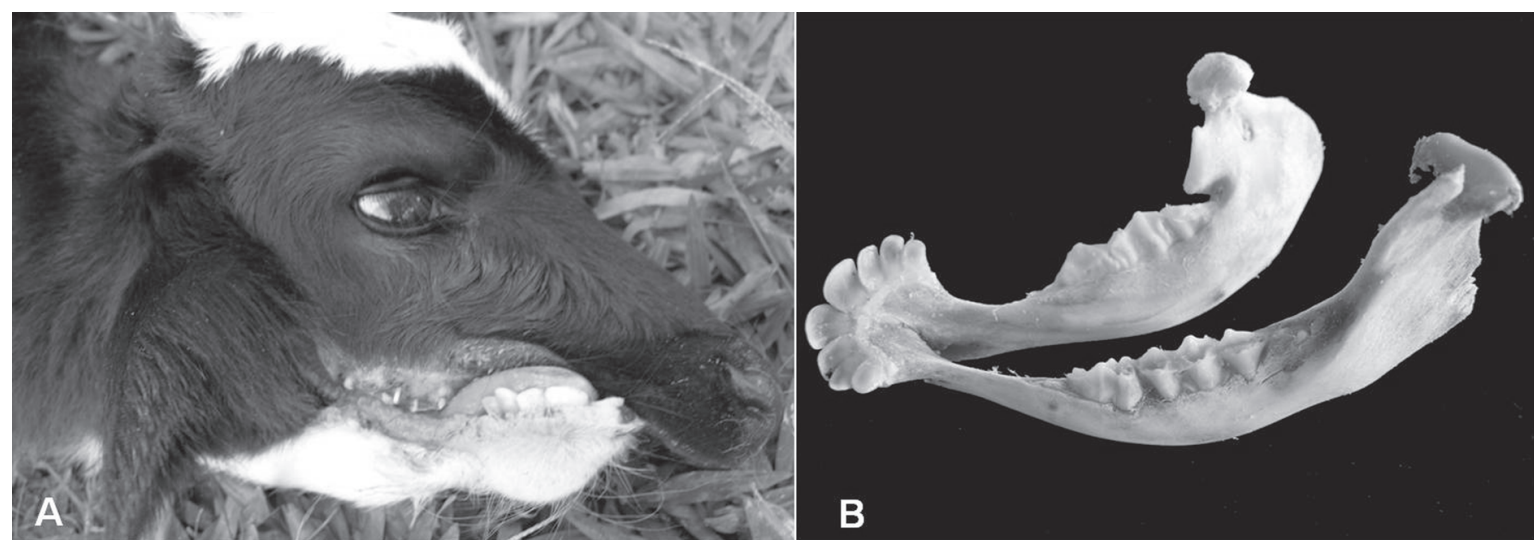

Fig.3. Desvio lateral da mandíbula (Bovino 32). (A) A mandíbula apresenta desvio para a direita e há malformação dos dentes que estão parcialmente inclusos. (B) $\mathrm{O}$ ramo ascendente direito da mandíbula apresenta hipoplasia dos processos cornoide e condilar.

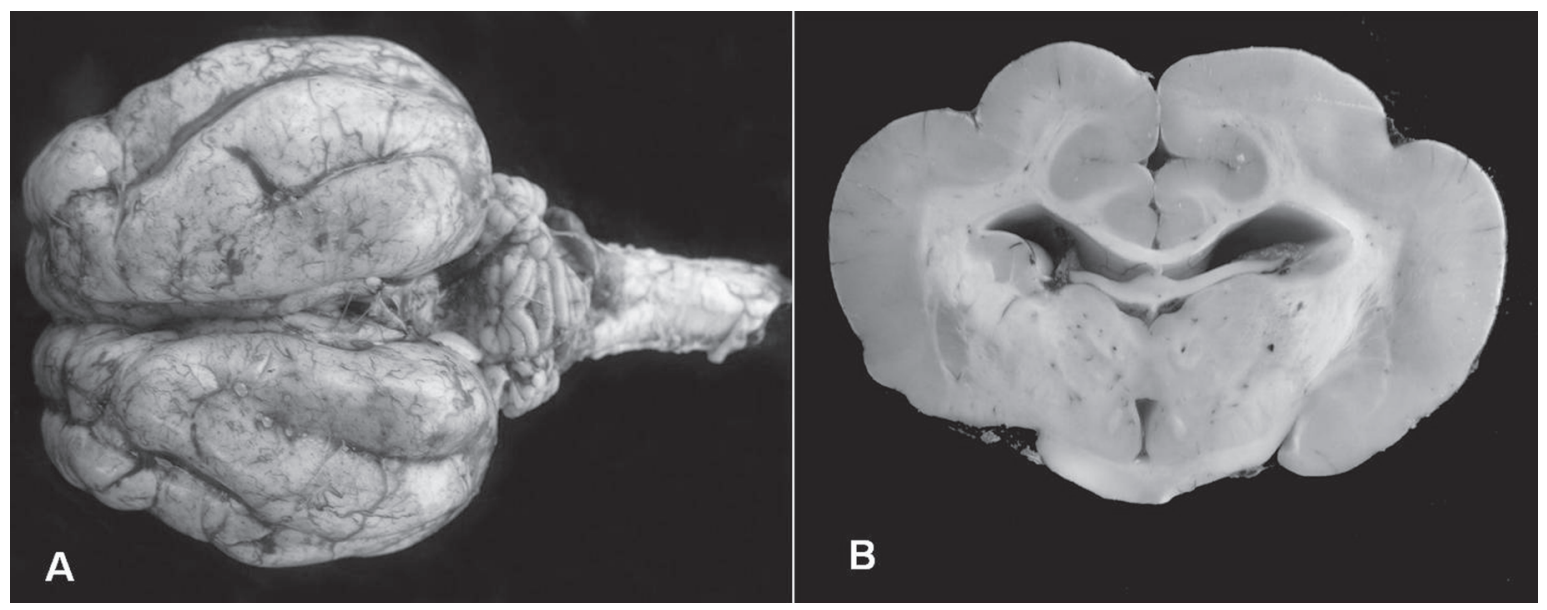

Fig.4.(A) Paquigiria (Bovino 42). O encéfalo apresenta os girus espessos e os sulcos escassos e pouco profundos, o cerebelo apresenta hipoplasia do verme e lobos anteriores. (B) Corte transversal do encéfalo na altura do tálamo apresentando o córtex liso e espesso com ausência dos girus e sulcos e substância branca estreita. 
temas estavam afetados (diprosopo). Em bovinos foram diagnosticadas diversas doenças hereditárias (hipermetria hereditária, artrogripose, hipoplasia linfática) ou suspeitas de serem hereditárias (condrodisplasia).

Os ovinos com diagnóstico de malformação congênita eram provenientes de estabelecimentos diferentes e foram os únicos casos ocorridos nas respectivas propriedades. Foram observados dois casos de gêmeos anômalos (Casos 1 e 2). O Caso 2 foi classificado como sincéfalo dípigos (monocéfalo tetrapos tetrabráquios) (Fig.6). O Ovino 3 apresentava aprosopia, que se caracteriza por ausência da mandíbula e do maxilar, astomia, arrinia (Fig.7) e sinotia.

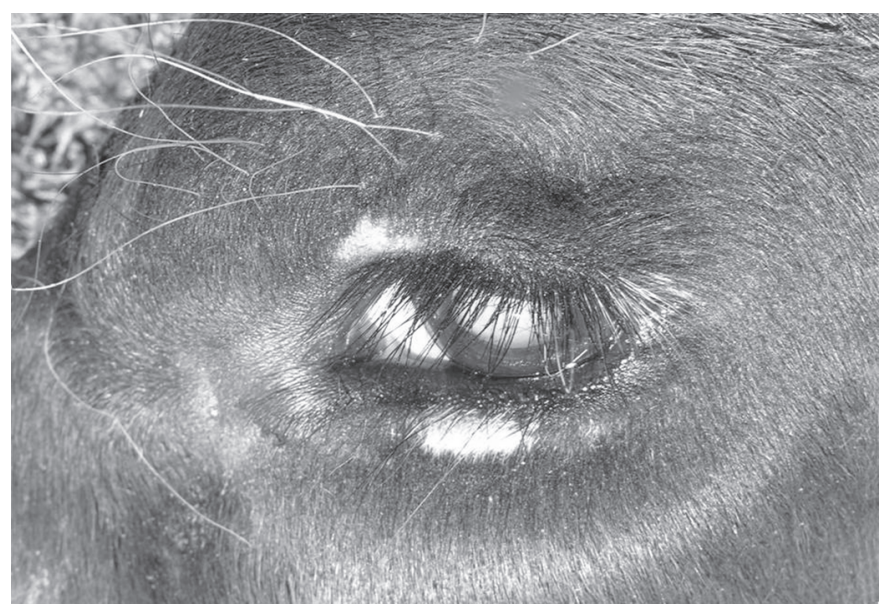

Fig.5. Catarata congênita (Bovino 11). Observa-se mancha branco-azulada no cristalino.

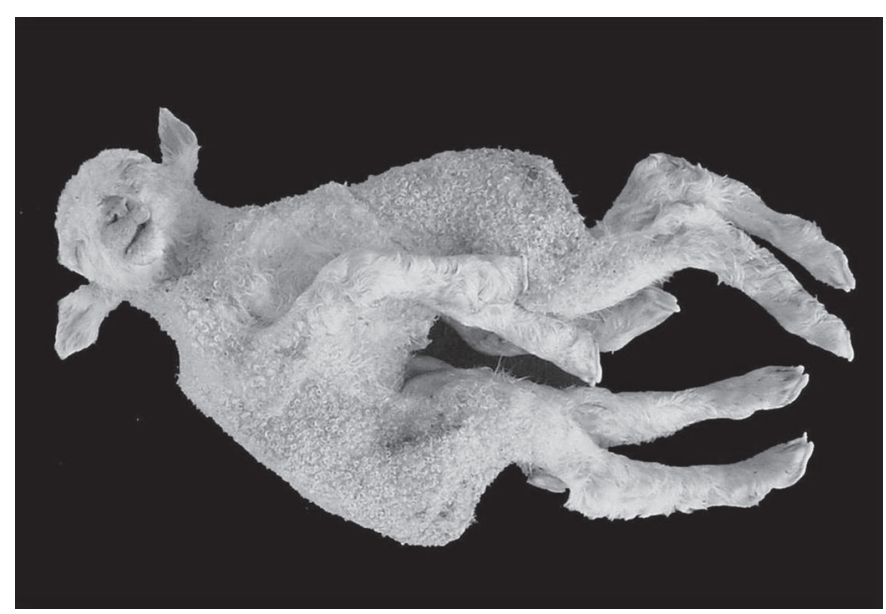

Fig.6. Gêmeos anômalos (Ovino 2). Observam-se dois corpos unidos pelo tórax com uma única cabeça. Há quatro pares de membros.

Todas as malformações observadas em búfalos foram diagnosticadas em um rebanho da raça Murrah pertencente a um estabelecimento no município de Capão do Leão (Casos $1,2,4,5,6,7$, e 8). Um caso foi observado em um rebanho da mesma raça de uma propriedade localizada no município de Pedro Osório (Caso 3). Duas enfermidades comprovadamente hereditárias foram descritas anteriormen- te: artrogripose (Schild et al. 2003) e dermatose mecânicobolhosa (Riet-Correa et al. 1994). Hidranencefalia foi descrita recentemente havendo fortes evidências de que seja também uma enfermidade hereditária (Fiss 2009).

Hiperplasia muscular (Fig.8) foi diagnosticada em duas propriedades sendo que no Caso 3 nasceram 25 animais

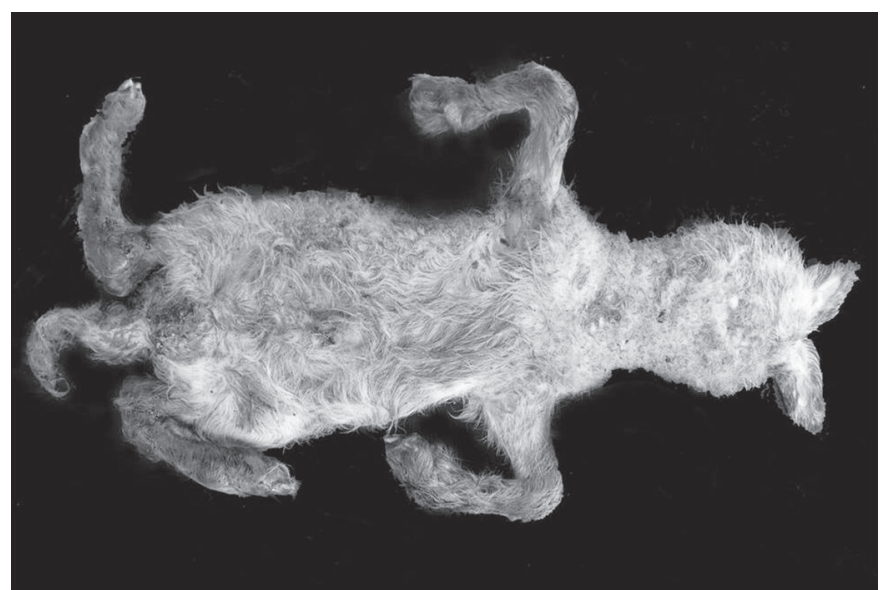

Fig.7. Aprosopia (Ovino 3). Não há formação da face e observam-se áreas alopécicas em várias regiões do corpo, as orelhas são unidas na base.

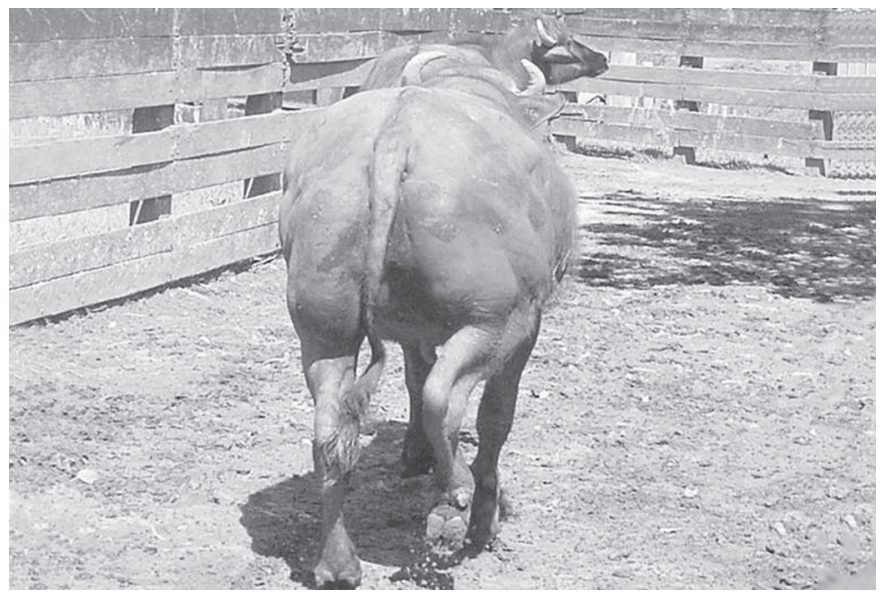

Fig.8. Miotonia hereditária (Búfalo 2). Há aumento de volume dos músculos semitendinoso e semimembranoso.

afetados em um período aproximado de 20 anos e o rebanho tinha búfalos provenientes da propriedade do município do Capão do Leão onde esta e as demais enfermidades foram diagnosticadas. Albinismo foi observado em 13 búfalos (Caso 4) que nasceram em anos alternados sendo que um deles era filho de pais também albinos. Todos os demais búfalos albinos na propriedade eram filhos de dois touros da raça Murrah importados da Bulgária, utilizados em inseminação artificial. Um búfalo apresentou albinismo e hidranencefalia (Caso 7) (Fig.9). O pai deste bezerro era o mesmo dos demais bovinos hidranencefálicos observados.

\section{DISCUSSÃO}

A ocorrência de defeitos congênitos em bovinos, ovinos e bubalinos na área de influência do Laboratório Regional de 


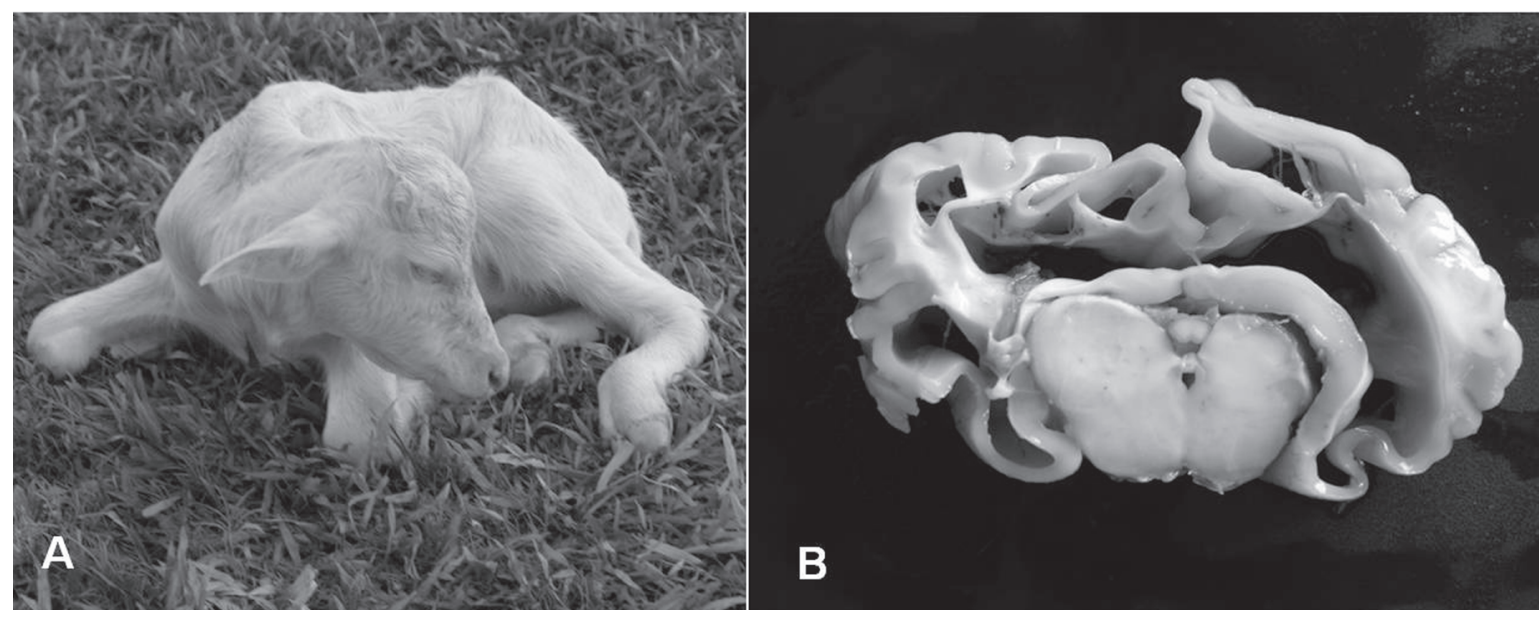

Fig.9. Albinismo e hidranencefalia (Búfalo 7). (A) Observa-se a pelagem branca, as mucosas rosadas e a cabeça em forma de cúpula. (B) Ao corte do encéfalo na altura do tálamo há cavidades císticas e ausência do tecido nervoso que foi substituído por líquido. O córtex é estreito e a substância branca reduzida.

Diagnóstico (LRD) da Faculdade de Veterinária, Universidade Federal de Pelotas (UFPel), representou 0,88\%, $0,36 \%$ e $7,54 \%$ respectivamente, de todos os materiais dessas espécies recebidos no LRD entre 1978 e 2009. Se considerarmos somente os animais necropsiados estes percentuais passam para $4,28 \%$ em bovinos, $0,97 \%$ em ovinos e 13,11\% em bubalinos. A estimativa de ocorrência de defeitos congênitos para bovinos e ovinos no mundo todo é de $0,2 \%-3 \%$ e $0,2 \%-2 \%$ respectivamente (Leipold \& Dennis 1986, Radostits et al. 2000). Na região central do Rio Grande do Sul, os defeitos no desenvolvimento representaram $0,54 \%$ dos diagnósticos realizados em bovinos e $0,34 \%$ de todos os materiais desta espécie recebidos no Laboratório de Patologia Veterinária da Universidade Federal de Santa Maria LPV/UFSM) entre 1964 e 2008 (Lucena et al. 2009).

Os defeitos congênitos esporádicos observados em bovinos no presente estudo representaram $45,83 \%$ dos casos, afetando um ou dois indivíduos em diferentes propriedades. Os defeitos congênitos hereditários e os provavelmente hereditários somados representaram 35,41\% dos diagnósticos. Por outro lado, o percentual de malformações associadas a causas ambientais, embora menor (16,66\%), causou prejuízos econômicos mais importantes pelo maior número de animais afetados por propriedade.

As malformações do sistema esquelético, do sistema muscular e do sistema nervoso central em bovinos foram as mais frequentes e representaram 43,75\%, 18,75\% e $18,75 \%$ do total de casos diagnosticados, respectivamente. Esses são os sistemas mais comumente afetados por malformações em bovinos (Leipold \& Dennis 1986). No estudo realizado no LPV/UFSM dos 23 casos de malformações congênitas observados $17,39 \%$ estavam relacionados ao SNC (Lucena et al. 2009). Nos animais domésticos as anormalidades congênitas do SNC são freqüentes e suas variações são mais numerosas do que as variações nas malformações que ocorrem em outros sistemas (Maxie \& Youssef 2007). Isso foi observado, também, no presente estudo, em que foram diagnosticadas sete diferentes malformações no SNC em um total de nove casos. Aparentemente, isso se deve ao alto grau de diferenciação e complexidade desse sistema o que aumenta a sua susceptibilidade ao desenvolvimento de anomalias (Maxie \& Youssef 2007).

Hipoplasia cerebelar afetou dois bovinos em uma mesma propriedade e a doença foi causada provavelmente por infecção materna pelo vírus da diarréia viral bovina (BVDV) em período crítico da gestação (Schild et al. 2001b). O surto de catarata congênita pode, também, ser atribuído à infecção pelo BVDV, embora isso não tenha sido definitivamente confirmado. Os defeitos oculares em conseqüência desta infecção descritos na literatura são microftalmia, atrofia ou displasia da retina e catarata (Ross et al. 1986; Yeruham et al. 2001). A mesma malformação aparentemente ocorreu em bovinos de outras propriedades e em todos os casos relatados o sêmen utilizado na reprodução dos rebanhos foi o mesmo (Sérgio Marcheriotto 2009, comunicação pessoal) e do qual foi isolado o vírus, o que sugere que a transmissão poderia ter ocorrido através do sêmen contaminado. Além disso, no Rio Grande do Sul, aproximadamente $35 \%$ dos bovinos e mais de $70 \%$ das propriedades já tiveram contato com este vírus (Flores \& Schuch 2007), demonstrando que o mesmo está disseminado no rebanho gaúcho. Estes fatos sugerem que os defeitos congênitos induzidos pela infecção pelo BVDV podem ser mais freqüentes do que se supõe e que a inseminação artificial, em alguns casos, poderia ser um meio de disseminação desses defeitos.

Degeneração cerebelar cortical em bovinos da raça Holandês foi descrita por Schild et al. (2001a) não sendo comprovada a origem hereditária da doença pelo retrocruzamento do touro suspeito com suas filhas, embora os autores não tenham descartado uma possível interação genético-ambiental para a causa da doença. Hipermetria hereditária dos bovinos Shorthorn (Caso 36) uma doença com sinais semelhantes aos observados na hipoplasia 
cerebelar, mas sem lesões cerebelares, transmitida por um gene recessivo autossômico, foi descrita por Schild et al. (1993).

Condrodisplasia tipo Telemark é um defeito congênito descrito na raça Jersey causado por um gene autossômico recessivo (Thompson 2007). Sete dos 11 bovinos diagnosticados com este defeito eram provenientes de pequenas propriedades produtoras de leite localizadas na bacia leiteira da região Sul do Estado, nas quais, frequentemente, é utilizado o mesmo touro por vários anos consecutivos, favorecendo a consanguinidade e, consequentemente, o aparecimento de defeitos transmitidos por genes recessivos.

Em quatro casos de artrogripose observados em bovinos da raça Holandês (Caso 4) foi comprovada a origem hereditária com transmissão por um gene recessivo autossômico. A frequência de $10,52 \%$ de animais nascidos com artrogripose no retrocruzamento de um touro suspeito de transmitir degeneração cerebelar cortical (Caso 26), com suas filhas é similar à frequência esperada para a transmissão por genes recessivos (12,50\%) (Leipold \& Dennis 1986). Artrogripose de origem hereditária foi descrita em bovinos da raça Charolês e atribuída a um gene recessivo autossômico em um estudo de três anos realizado em rebanhos no Canadá (Naurot et al. 1980). Artrogripose, em geral associada a outras malformações, é atribuída, também, à infecção de fêmeas prenhes em determinado período da gestação por certos vírus como o vírus da língua azul (BTV), o vírus da doença da fronteira (border disease), o vírus da febre do vale do Cache, (Van Vleet \& Valentine 2007), o BVDV (Pavarini et al. 2008) e o vírus de Akabane (Leipold et al. 1993), dos quais os únicos que têm sido identificados no Brasil são o BVDV e o BTV. Neste trabalho os demais casos de artrogripose foram esporádicos e não foi possível determinar suas causas, no entanto no Caso 5 não se descarta a possibilidade de infecção viral já que o bezerro afetado era do mesmo rebanho dos bovinos com hipoplasia cerebelar de provável origem viral (Caso 39) (Schild et al. 2001b).

Os cinco casos de gêmeos anômalos caracterizados como diprosopo e dicéfalo dipos dibráquios ocorreram de forma esporádica, sendo os bovinos afetados provenientes de propriedades localizadas em diferentes municípios da área de influência do LRD. Nos poucos relatos sobre essas malformações em bovinos as causas não têm sido identificadas e tampouco se sabe se essa anomalia é mais freqüente nas raças que têm tendência hereditária a produzirem gêmeos (Leipold \& Dennis 1972). É mencionado, também, em um estudo de 50 casos de gêmeos anômalos que o maior número de animais afetados foi concebido durante o inverno (Leipold \& Dennis 1972). Nos casos relatados neste trabalho todos os bovinos afetados foram concebidos na primavera.

Hipoplasia linfática hereditária foi descrita em bovinos Hereford causada por um gene dominante de penetrância incompleta e expressividade variável (Schild et al. 1991). Esta mesma doença foi descrita na raça Angus na região central do Estado causada aparentemente por um gene recessivo autossômico (Macêdo et al. 2009).

Hipomielinogênese congênita por deficiência de cobre ocorreu de forma coletiva em duas propriedades da região sul do Rio Grande do Sul tendo sido demonstrada a deficiência deste mineral em um dos bovinos afetados (RietCorrea et al. 1993). Ambas as propriedades eram localizadas em áreas próximas à Lagoa Mirim onde o solo é pobre e comprovadamente carente em cobre (Gavillon \& Quadros 1976).

No presente trabalho apesar de não ter sido confirmada a ocorrência de um surto de fenda palatina em bovinos (Caso 35) o fato de terem morrido três outros animais na propriedade no mesmo período com os mesmos sinais clínicos sugere que o defeito pode ter sido causado pela administração pour-on de Acatax (Fluazuron) e mebendazole realizada nas novilhas prenhes. Teratogênese em ruminantes tem sido descrita pela ação de princípios ativos como mebendazol, parbendazol, albendazol entre outros causando diferentes malformações como ciclopia, artrogripose, escoliose, ectopia renal e outros (Delatour 1983). Outra possibilidade seria a ingestão de alguma substância tóxica contendo alcaloides piperidínicos. Fenda palatina associada a outras malformações ósseas é um defeito freqüente nas intoxicações por plantas que contém estes alcalóides como Conium maculatum, Lupinus spp. e Nicotiana glauca (Panter et al. 1998).

Persistência do ducto arterioso representou $4,16 \%$ dos diagnósticos de malformações observadas na área de influência do LRD. Um percentual de $35,7 \%$ de persistência do ducto arterioso foi observado em bovinos Hereford e Holandês de um total de 14 defeitos cardíacos observados em 36 animais (Gopal et al. 1986). No presente estudo os animais com persistência do ducto arterioso eram das raças Aberdeen Angus e Jersey. Desvio lateral da mandíbula (Casos 8 e 32) representou $4,16 \%$ dos diagnósticos e não foram encontradas descrições de defeito similar na literatura consultada. Um dos defeitos esqueléticos descritos que acomete os ossos da face é a campilognatia; entretanto nesse defeito o desvio ocorre no osso maxilar e a mandíbula é normal (Leipold \& Dennis 1983), ao contrário do observado nos dois bovinos com defeitos nos ossos da face descritos no presente trabalho.

$\mathrm{Na}$ espécie ovina é provável que o número de malformações congênitas seja maior. Em um estudo para identificar as causas de morte perinatal em cordeiros na região sul do Rio Grande do Sul foi encontrado 0,8\% de mortes por defeitos no desenvolvimento (Méndez et al. 1982). Provavelmente, cordeiros nascidos com malformações congênitas não sejam remetidos ao laboratório para diagnósti$\mathrm{co}$, principalmente se o percentual de mortalidade perinatal está dentro do limite esperado, em torno de $10 \%$, nas condições de criação de ovinos na região Sul do Estado (Méndez et al. 1982). Essa é uma das causas do pouco conhecimento sobre os defeitos congênitos que ocorrem nas diversas espécies animais em todo mundo (Leipold et al. 1972). 
Os três casos de malformações congênitas em ovinos descritos no presente trabalho ocorreram de forma esporádica sem determinação das causas. Um dos dois gêmeos anômalos observados era do tipo sincéfalo dípigos (monocéfalo tetrapos tetrabráquios). Esta anomalia em geral causa distocia e o conhecimento sobre sua etiologia é escasso. Em um trabalho sobre a ocorrência de duplicação embrionária em ovinos os autores não observaram evidências de causa ambiental ou genética (Dennis 1975).

Aprosopia observada em um ovino tinha características similares aos casos descritos por Dennis \& Leipold (1972). Essa malformação é rara em animais domésticos e foi sugerido pelos mesmos autores que seria uma forma extrema de agnatia, afetando a mandíbula e maxilar.

Frequentemente, os relatos de malformações congênitas em ovinos, especialmente relacionados ao sistema esquelético, envolvem casos isolados ou grupos de animais em uma propriedade específica e a indisponibilidade de dados genealógicos não permite a identificação da origem desses defeitos (Thompson et al. 2008).

Em bubalinos, a frequência de defeitos congênitos de $13,11 \%$ é aparentemente alta se considerarmos que a maioria dos casos foi observada em um mesmo rebanho. Os sistemas mais frequentemente afetados foram o muscular e o tegumentar ambos representando $37,5 \%$ dos casos. A maioria das enfermidades observadas são reconhecidamente hereditárias ou tiveram a origem hereditária comprovada como dermatose mecânico-bolhosa (RietCorrea et al. 1994) e artrogripose (Schild et al. 2003).

Miotonia hereditária foi observada também no Pará em búfalos da raça Murrah e é uma doença hereditária, causada pela mutação no gene CLCN1 (Borges et al. 2006). Hidranencefalia/hipoplasia cerebelar é outra enfermidade descrita em búfalos que apresenta fortes evidências de ser hereditária (Fiss 2009).

Albinismo (Caso 5) é um defeito congênito hereditário descrito em diversas espécies domésticas causado por gene recessivo (Leipold \& Dennis 1986). Em bubalinos, albinismo foi descrito em uma província da China com uma prevalência de 30\% (Levine 1925); entretanto neste caso aparentemente os búfalos não são albinos verdadeiros uma vez que tinham pigmentação nos olhos e alguns eram malhados e seriam búfalos albinoides segundo Cockrill (1974). No caso descrito neste estudo os búfalos foram diagnosticados como albinos verdadeiros (ausência total de pigmentação) e nasceram em anos alternados, todos originários de dois reprodutores importados da Bulgária o que sugere fortemente a transmissão hereditária do defeito.

Megaesôfago afetou três búfalos no ano 1995 e posteriormente não foi mais observada no rebanho, entretanto não se pode descartar completamente a possibilidade de herança genética como causa, já que genes recessivos podem se manifestar esporadicamente e, muitas vezes, têm expressividade variável e penetrância incompleta e os animais apresentam sinais clínicos e/ou lesões que podem passar despercebidos (Leipold \& Dennis 1986).

A ocorrência de pelo menos cinco enfermidades here- ditárias ou com fortes evidências de transmissão genética em bubalinos deve-se, provavelmente, à alta consanguinidade existente no rebanho bubalino brasileiro, principalmente nos da raça Murrah. As mais de 3.000 .000 de cabeças existentes hoje no Brasil são originárias de aproximadamente 200 animais importados, na sua grande maioria, da Índia na década de 60. A última importação oficial de bubalinos da Ásia ocorreu em 1962, em razão de uma lei que proibia a importação de material genético daquele continente devido a problemas sanitários (Miranda 1986).

Com base nos resultados obtidos neste trabalho é possível afirmar que os defeitos congênitos esporádicos cuja etiologia não é identificada embora mais frequentes têm pouca importância econômica em bovinos na região Sul do Rio Grande do Sul. Por outro lado, as doenças provavelmente hereditárias, como a condrodisplasia, que ocorre em bovinos Jersey em pequenas propriedades rurais da bacia leiteira da região, são importantes pela mortalidade de animais, e pela possibilidade de disseminação de genes indesejáveis. Defeitos congênitos ambientais induzidos, por exemplo, por infecções virais podem causar importantes prejuízos econômicos em determinados estabelecimentos ou regiões. Em razão da alta consanguinidade em búfalos Murrah, devem ser adotadas medidas de controle para evitar-se a contínua disseminação, principalmente dos genes recessivos que são mais difíceis de controlar.

Agradecimentos.-Trabalho financiado pelo CNPq, Processo no 506664/2010-4.

\section{REFERÊNCIAS}

Borges A.S., Mota L.L., Barbosa D., Magno C., Martions R.A., Teixeira R., Mortari A.C., Rahal S. \& Resende L.A. 2006. Nova desordem miotônica em búfalos: descrição clínica e eletromiográfica. Resumos $6^{\circ}$ Encontro da Sociedade Brasileira de Investigação Neurológica, Ribeirão Preto, SP.

Castro M.B., Szabó M.P.J., Moscardini A.R.C. \& Borges J.R.J. 2008. Perosomus elumbis em um cordeiro no Brasil. Ciência Rural 38(1): 262-265.

Cockrill R. 1974. Observations on skin colour and hair patterns, p.4856. In: Cockrill R. (Ed.), The Husbandry and Health of the Domestic Buffalo. Food and Agriculture Organization of the United Nations, Rome.

Dantas A.F.M., Riet-Correa F., Medeiros R.M.T., Galiza G.J.N., Pimentel L.A., Anjos B.L. \& Mota R.A. 2010. Malformações congênitas em ruminantes no semiárido do Nordeste Brasileiro. Pesq. Vet. Bras. 30(10):807-815.

Delatour P. 1983. Some aspects of the teratogenicity of veterinary drugs. Vet. Res. Commun. 7:125-131.

Dennis S.M. 1975. Embryonic duplications in sheep. Aust. Vet. J. 51:8387.

Dennis S.M. \& Leipold H.W. 1972. Aprosopia (facelessness) in lambs. Vet. Rec. 90:365-367

Fiss L. 2009. Hidranencefalia e hipoplasia cerebelar em búfalos Murrah. Dissertação de Mestrado em Patologia Veterinária, Faculdade de Medicina Veterinária, Universidade Federal de Pelotas, Pelotas, RS. 59p.

Flores E.F. \& Schuch L.F.D. 2007. Diarréia viral bovina, p.169-173. In: Riet-Correa F., Schild A.L., Lemos R.A.A. \& Borges J.R.J. (Eds), Doenças de Ruminantes e Equídeos. Pallotti, Santa Maria, RS.

Gavillon O. \& Quadros A.T. 1976. O cobre, o molibdênio e o sulfato 
inorgânico em pastagens nativas do Rio Grande do Sul. Anuário Técnico do IPZFO, Porto Alegre, 3:423-453.

Gopal T., Leipold H.W. \& Dennis S.M. 1986. Congenital cardiac defects in calves. Am. J. Vet. Res. 47:1120-1121.

Jolly R.D. 2002. Screening for genetic diseases in cattle. Aust. Vet. J. 80(5):284-285

Leipold H.W. \& Dennis S.M. 1986. Congenital defects affecting bovine reproduction, p.177-199. In: Morrow D.A. (Ed.), Current Therapy in Theriogenology: Diagnosis, treatment and prevention of reproductive diseases in small and large animals. W.B. Saunders Company, Philadelphia.

Leipold H.W., Dennis S.M. \& Huston K. 1972. Congenital defects of cattle: Nature, cause, and effect. Adv. Vet. Sci. Comp. Med. 16:103150.

Leipold H.W., Hiraga T. \& Dennis S.M. 1993. Congenital defects of the bovine musculoskeletal system and joints. Vet. Clin. North Am., Food Anim. Pract. 9:93-104.

Leipold H.W., Huston K. \& Dennis S.M. 1983. Bovine congenital defects. Adv. Vet. Sci. Comp. Med. 27:197-271.

Lucena R.B., Pierezan F., Kommers G.D., Irigoyen L.F., Fighera R.A. \& Barros C.S.L. 2010. Doenças de bovinos no sul do Brasil: 6.706 casos. Pesq. Vet. Bras. 30(5):428-434.

Macêdo J.T.S.A., Lucena R.B., Tochetto C., Oliveira Filho J.C., Pierezan F., Irigoyen L.F. \& Barros C.S.L. 2009. Linfedema primário congênito em bovinos Red Angus. Pesq. Vet. Bras. 29:713-718.

Magalhães V.R., Santana A.F., Oliveira A.C., Wicke A.A. \& Barone M.M. 2008. Levantamento da ocorrência de anomalias da mandíbula em caprinos e ovinos, encontrada em cinco municípios da microrregião de Irecê (BA). Ciênc. Anim. Bras. 9(2):341-345.

Maxie M.G. \& Youssef S. 2007. Nervous system, p.281-458. In: Maxie M.G. (Ed.), Jubb, Kennedy, and Palmer's Pathology of Domestic Animals. Vol.1. $5^{\text {th }}$ ed. Saunders Elsevier, Philadelphia.

Méndez M.C., Riet-Correa F., Ribeiro J., Selaive A. \& Schild A.L. 1982. Mortalidade perinatal em ovinos nos municípios de Bagé, Pelotas e Santa Vitória do Palmar, Rio Grande do Sul. Pesq. Vet. Bras. 2:6976.

Miranda W.C. 1986. A Criação de Búfalos no Brasil. Criadores, São Paulo. 173p.

Nawrot P.S., Howell W.E. \& Leipold H.W. 1980. Arthrogryposis: An inherited defect in newborn calves. Aust. Vet. J. 56:359-364.

Panter K.E., Gardner D.R., Shea R.E., Molyneux R.J. \& James L.F. 1998. Toxic and teratogenic piperidine alkaloids from Lupinus, Conium and Nicotiana species, p.345-350. In: Garland T. \& Barr A.C. (Eds.), Toxic Plants and Other Natural Toxicants. CAB International, New York.

Pavarini S.P., Sonne L., Antoniassi N.A.B., Santos A.S., Pescador C.A., Goberllini L.G. \& Driemeier D. 2008. Anomalias congênitas em fetos bovinos abortados no sul do Brasil. Pesq. Vet. Bras. 28:149154.

Pimentel L.A., Riet Correa F., Gardner D., Panter K.E., Dantas A.F.M., Medeiros R.M.T., Mota R. A. \& Araújo J.A.S. 2007. Mimosa tenuiflora as a cause of malformations in ruminants in the northeastern Brazilian semiarid rangelands. Vet. Pathol. 44(6):928-931.

Radostits O.M., Gay C.C., Blood D.C. \& Hinchcliff K.W. 2000. Congenital defects, p.120-125. In: Ibid. (Eds), Veterinary Medicine: A textbook of the diseases of cattle, sheep, pigs, goats and horses. $9^{\text {th }}$ ed. W.B. Saunders, Philadelphia.

Riet-Correa F., Bondan E.F., Mendez M.C., Moraes S.S. \& Concepción M.R. 1993. Efeito da suplementação com cobre e doenças associadas à carência de cobre em bovinos no Rio Grande do Sul. Pesq. Vet. Bras. 13:45-49.

Riet-Correa F., Barros S.S., Damé M.C. \& Peixoto P.V. 1994. Hereditary suprabasilar acantholytic mechanobullous dermatosis in buffaloes (Bubalus bubalis). Vet. Pathol. 31:450-454.

Ross C.E., Dubovi E.J., Donis R.O. 1986. Herd problem of abortions and malformed calves attributed to bovine viral diarrhea. J. Am. Vet. Med. Assoc.188:618-619.

Schild A.L., Riet-Correa F. \& Méndez M.C. 1991. Hereditary lymphedema in Hereford cattle. J. Vet. Diagn. Invest. 3:47-51.

Schild A.L., Riet-Correa F., Mendez M.C. \& Barros S.S. 1993. Hereditary hypermetria in Shorthorn cattle. J. Vet. Diagn. Invest.5:640-642.

Schild A.L., Carapeto L.P., Riet-Correa F., Méndez M.C. \& Guerreiro G. 1996. Radiological study of hereditary lynphedema in Hereford cattle. Pesq. Vet. Bras. 16:21-26.

Schild A.L., Riet-Correa F., Portiansky E.L., Méndez M.C. \& Graça D.L. 2001a. Congenital cerebelar cortical degeneration in Holstein cattle in southern Brazil. Vet. Res. Commun. 25: 89-195.

Schild A.L., Riet-Correa F., Fernandes C.G., Damé M.C. \& Graça D.L. 2001b. Hipoplasia cerebelar e porencefalia em bovinos Charolês no sul do Rio Grande do Sul. Ciência Rural 31:149-153.

Schild A.L., Soares M.P., Damé M.C., Portiansky E. \& Riet-Correa F. 2003. Arthrogryposis in Murrah buffaloes in southern Brazil. Pesq. Vet. Bras. 23:13-16.

Thompson K. 2007. Bones and joints, p.1-184. In: Maxie M.G. (Ed.), Jubb, Kennedy, and Palmer's Pathology of Domestic Animals. Vol.1. $5^{\text {th }}$ ed. Saunders Elsevier, Philadelphia.

Thompson K.G., Piripi S.A. \& Dittmer K.E. 2008. Inherited abnormalities of skeletal development in sheep. Vet. J. 177: 324-333.

Van Vleet J.F. \& Valentine B. 2007. Muscle and tendon, p.185-280. In: Maxie M.G. (Ed.), Jubb, Kennedy, and Palmer's Pathology of Domestic Animals. Vol.1. $5^{\text {th }}$ ed. Saunders Elsevier, Philadelphia.

Yeruham I., Michael M. \& Perl P. 2001. An usual congenital malformation in a calf with serological evidence of foetal bovine viral diarrhea virus infection. Acta Vet. Scand. 42:425-428. 